\title{
A Short Biography of Israel Moiseevich Gelfand
}

Israel Moiseevich Gelfand (1913-2009) was one of the giants of 20th century mathematics. He made fundamental contributions to several branches of mathematics.

Gelfand was born in the small town of Okny in Ukraine in 1913. He was a bright student. Though he was thrown out of high school for political reasons, some years later he secured direct admission to Moscow State University for post-graduate study. His doctoral guide was none other than A N Kolmogorov, another mathematical giant. Apparently their approaches to mathematics were quite distinct. Comparing the two men, a colleague of Gelfand observed that were they to find themselves in a mountainous country: "Kolmogorov would immediately try to climb the highest mountain. Gelfand would immediately start to build roads." This is to say that the work of Gelfand paved the way for further research for several mathematicians.

Gelfand ran a legendary mathematical seminar series in Moscow State University. Lectures were often impromptu and different areas of mathematics got developed then and there through these discussions! In 1986 he emigrated to the United States. Gelfand took talented mathematicians as students and collaborators, and many of them became famous mathematicians. Endre Szemerédi, Alexandre Kirillov, Georgiy Shilov were among his doctoral students. According to an online database, Gelfand had 23 students and as of now 336 descendants.

Gelfand's work in representation theory is crucial for physicists working in Quantum Mechanics. Similarly his work in integral geometry has given the mathematical framework for the field of medical imaging known as Tomography. His results on $\mathrm{C}^{*}$-algebras and representation theory are now part of university texts.

Gelfand held several honorary degrees and was awarded the Order of Lenin three times for his research. He was a member of several academies and won many honors such as the Wolf Prize, Kyoto Prize, MacArthur Foundation Fellowship.

Gelfand died on October 5, 2009. As is said, he is probably the last of the greatest who worked in almost every area of Mathematics. According to Gelfand, Mathematics is like classical music: "The combination of these four things: beauty, exactness, simplicity and crazy ideas is just the heart of mathematics, the heart of classical music".

Rajarama Bhat

Statistics and Mathematics Unit

Indian Statistical Institute, 8th Mile Mysore Road, RVCE Post, Bangalore 560 059, India.

Email:bhat@isibang.ac.in 